\title{
Odd-numbered perfluorocarboxylates predominate over perfluorooctanoic acid in serum samples from Japan, Korea and Vietnam
}

\section{$\operatorname{AUTHOR}(\mathrm{S})$ :}

Harada, Kouji H.; Hitomi, Toshiaki; Niisoe, Tamon;

Takanaka, Katsunobu; Kamiyama, Sigetosi; Watanabe, Takao; Moon, Chan-seok; Yang, Hye-ran; Hung, Nguyen Ngoc; Koizumi, Akio

\section{CITATION:}

Harada, Kouji H. ...[et al]. Odd-numbered perfluorocarboxylates predominate over perfluorooctanoic acid in serum samples from Japan, Korea and Vietnam. Environment International 2011, 37(7): 1183-1189

\section{ISSUE DATE:}

2011-10

URL:

http://hdl.handle.net/2433/143676

\section{RIGHT:}

(C) 2011 Elsevier Ltd.; This is not the published version. Please cite only the published version.; この論文は出版社版でありません。引用の際に は出版社版をご確認ご利用ください。 
1 Odd-numbered perfluorocarboxylates predominate over perfluorooctanoic acid in

2

4 Kouji H. Harada ${ }^{a}$, Toshiaki Hitomi ${ }^{a}$, Tamon Niisoe ${ }^{a}$, Katsunobu Takanaka ${ }^{\text {b }}$, Sigetosi

5 Kamiyama $^{\mathrm{c}}$, Takao Watanabe ${ }^{\mathrm{d}}$, Chan-seok Moon ${ }^{\mathrm{e}}$, Hye-ran Yang ${ }^{\mathrm{a}}$, Nguyen Ngoc Hung ${ }^{\mathrm{f}}$,

6 Akio Koizumi ${ }^{\text {a, }}$

$7 \quad{ }^{\text {a }}$ Department of Health and Environmental Sciences, Kyoto University Graduate School

8 of Medicine, Yoshida, Kyoto 606-8501, Japan

9 b Department of Neurosurgery, Takayama Red Cross Hospital, Takayama 506-8550,

10 Japan

$11{ }^{\mathrm{c}}$ Morinomiyako Industrial Health Association, Miyagino, Sendai 983-0031, Japan

12 Tohoku Bunkyo College, Katayachi, Yamagata 990-2316, Japan

$13{ }^{\mathrm{e}}$ Department of Industrial Health, Catholic University of Pusan, Busan 609757, Korea

$14{ }^{\mathrm{f}}$ Department of Science and Technology, Hanoi Medical University, Ton That Tung,

15 Hanoi, S.R. Vietnam

16 *Correspondence to: Akio Koizumi M.D., Ph.D.

17 Department of Health and Environmental Sciences, Kyoto University Graduate School

18 of Medicine, Yoshida Konoe, Sakyo, Kyoto 606-8501, Japan

19 Tel: +81-75-753-4456; Fax: +81-75-753-4458

20 E-mail: koizumi.akio.5v@kyoto-u.ac.jp 


\section{Abstract}

Perfluorooctanoic acid (PFOA) has recently attracted attention as a potential health risk following environmental contamination. However, information detailing exposure to perfluorinated carboxylic acids (PFCAs) other than PFOA is limited. We measured the concentrations of PFCAs (from perfluorohexanoic acid to perfluorotetradecanoic acid) in serum samples obtained from patients in Japan (Sendai, Takayama, Kyoto and Osaka) between 2002 and 2009, Korea (Busan and Seoul) between 1994 and 2008 and Vietnam (Hanoi) in 2007/2008. Total PFCAs levels (geometric mean) were increased from 8.9 ng $\mathrm{mL}^{-1}$ to $10.3 \mathrm{ng} \mathrm{mL}^{-1}$ in Japan; from $7.0 \mathrm{ng} \mathrm{mL}^{-1}$ to $9.2 \mathrm{ng} \mathrm{mL}^{-1}$ in Korea; and were estimated at $4.7 \mathrm{ng} \mathrm{mL} \mathrm{m}^{-1}$ in Vietnam. PFCAs of greater length than PFOA were significantly increased in Sendai, Takayama and Kyoto, Japan, and levels of long-chain PFCAs exceeded PFOA levels in serum. Among these PFCAs, perfluoroundecanoic acid (PFUnDA) was the predominant component (28.5\%), followed by perfluorononanoic acid (PFNA 17.5\%), perfluorodecanoic acid (PFDA 7.9\%), perfluorotridecanoic acid (PFTrDA 6.1\%) and perfluorododecanoic acid (PFDoDA $1.8 \%$ ). Odd-numbered PFCAs (PFNA, PFUnDA and PFTrDA) were also observed in Korea and Vietnam and their presence increased significantly in Korea between 1994 and 2007/2008. The proportion of long-chain PFCAs in serum was relatively high compared to reports in Western countries. Further investigations into the sources and exposure routes are needed to predict the future trajectory of these serum PFCA levels.

Key words: perfluorocarboxylate; perfluorooctanoic acid; serum; temporal trend; East Asia 


\section{Abbreviations}

45 PFCAs: perfluorinated carboxylic acids

46 PFOS: perfluorooctane sulfonate

47 PFOA: perfluorooctanoic acid

48 PFHxA: perfluorohexanoic acid

49 PFHpA: perfluoroheptanoic acid

50 PFNA: perfluorononanoic acid

51 PFDA: perfluorodecanoic acid

52 PFUnDA: perfluoroundecanoic acid

53 PFDoDA: perfluorododecanoic acid

54 PFTrDA: perfluorotridecanoic acid

55 PFTeDA: perfluorotetradecanoic acid

56 IDLs: instrumental detection limits

57 MDLs: method detection limits

58 RSD: relative standard deviation

59 SD: standard deviation

60 GM: geometric mean

61 GSD: geometric standard deviation

62 


\section{Introduction}

Perfluorinated compounds such as perfluorooctane sulfonate (PFOS) and perfluorooctanoic acid (PFOA) have recently attracted attention owing to widespread contamination of the environment, wildlife and humans by these chemicals (Houde et al., 2006). In 2002, after 50 years of production, 3M Company phased out their manufacture of PFOS (Renner, 2001). PFOA is considered to be a major component of perfluorocarboxylates (PFCAs) emission. However, in Japan, PFCA emissions consisted of not only PFOA but also perfluorononanoic acid (PFNA) and perfluoroundecanoic acid (PFUnDA) (of which 25 and 7 metric tons, respectively, were emitted in 2000) (Prevedouros et al., 2006). These odd-numbered PFCAs (PFNA, PFUnDA and perfluorotridecanoic acid (PFTrDA)) were detected at higher concentrations in samples from local wildlife than similar even-numbered PFCAs (PFOA, perfluorodecanoic acid (PFDA) and perfluorododecanoic acid (PFDoDA), respectively) (Furdui et al., 2008). Although studies using human samples from Western countries showed that PFOA was the most prevalent (followed by PFNA, PFDA and PFUnDA) (Haug et al., 2009; Joensen et al., 2009; Kato et al., 2009), our previous study of Japanese women in the Miyagi prefecture showed that PFNA and PFUnDA (average: 2.8 and $5.4 \mathrm{ng} \mathrm{mL} \mathrm{mL}^{-1}$, respectively) were found at broadly similar serum concentrations to PFOA (average: 4.9 ng mL ${ }^{-1}$ ) (Kärrman et al., 2009).

PFCAs with longer chains than PFOA have higher bio-concentration factors suggesting persistency in the environment (Martin et al., 2003). Temporal trends in serum levels after 2002 showed no apparent decline of PFNA, PFDA or PFUnDA in Norway (Haug et al., 2009), although serum levels of PFOA and PFOS both decreased in the United States, Norway and Japan (Harada and Koizumi, 2009; Harada et al., 
2010; Haug et al., 2009; Olsen et al., 2008). These findings suggest a possibility that the origin and source of exposure to long-chain PFCAs could differ from those of PFOA and PFOS.

In the present study, we investigated current serum concentrations of PFCAs in three Asian countries (Japan, Korea and Vietnam). We selected the cities of Busan and Seoul in Korea because they are comparably urban and industrialized to Osaka, Japan. To confirm the temporal trends in Japan and Korea, we used archived historical serum samples stored in the human specimen bank (Koizumi et al., 2009; Koizumi et al., 2005). Hanoi in Vietnam was selected to evaluate the development of PFCA contamination following recent industrialization.

\section{Material and methods}

\subsection{Experimental design and study population}

To evaluate geographical differences and temporal trends in Asian countries, we compared 521 samples collected from Japan (Sendai, Takayama, Kyoto and Osaka) between 2002 and 2009; Korea (Busan and Seoul) between 1994 and 2008; and in Hanoi, Vietnam between 2007 and 2008. Samples from Sendai and Takayama in 2008, Osaka, Busan, Seoul and Hanoi are identical to a previous analysis of PFOS and PFOA (Harada et al., 2010; Kärrman et al., 2009). A total of 521 serum samples with information on donor age, sex and residential history ( $>5 \mathrm{yr}$ in each area) were selected from the archived samples in Kyoto Human Specimen Bank (Koizumi et al., 2009; Koizumi et al., 2005) (Table 1). Serum was separated from cellular components and stored at $-30{ }^{\circ} \mathrm{C}$ until analysis.

The study population in Osaka and Kyoto consisted of residents that had been 
111 intensely exposed to PFOA from a local industrial source (the fluoropolymer

112 manufacturer, Daikin Company) (Harada et al., 2004, 2007, 2010; Kärrman et al., 2009;

113 Niisoe et al., 2010). In contrast, there is no known potential industrial source of PFCAs

114 that would affect sample populations in the other cities studied.

115 For historical comparisons, samples were selected so that age and gender were matched among time points, except for Busan in 2000 and Osaka (Table 1).

117 The research protocol for the present study was reviewed and approved by the

118 Ethics Committee of the Kyoto University Graduate School of Medicine on 14 119 November 2003 (E25).

\subsection{Reagents}

Ammonium acetate (purity: $>99 \%$ by HPLC) was purchased from Aldrich (Steinheim, Germany). Acetonitrile (LC-MS grade) and water (distilled LC-MS grade) were obtained from Kanto Chemicals (Tokyo, Japan). Acetic acid and benzyl bromide were purchased from Wako pure chemicals (Osaka, Japan). Mixture of native PFCAs,

${ }^{13} \mathrm{C}_{4}$-labeled PFOA and ${ }^{13} \mathrm{C}_{5}$-labeled PFNA were obtained from Wellington Laboratories (Guelph, Ontario, Canada).

\subsection{Determination of PFCAs in serum}

Perfluorohexanoic acid (PFHxA), perfluoroheptanoic acid (PFHpA), PFOA, PFNA, PFDA, PFUnDA, PFDoDA, PFTrDA and perfluorotetradecanoic acid (PFTeDA) were analyzed. Serum samples were subjected to a clean-up procedure using a dispersive carbon method described by Powley et al. (2005). Briefly, the serum samples $(0.5 \mathrm{~mL}$, except for Korean samples between 1994 and 2000, which were $0.25 \mathrm{~mL}$ ) together with 
an internal standard $\left({ }^{13} \mathrm{C}_{4}\right.$-PFOA, $\left.1 \mathrm{ng}\right)$ were extracted with $5 \mathrm{~mL}$ of acetonitrile, followed by centrifugation at $1600 \times g$ for $15 \mathrm{~min}$. The supernatants were transferred into new tubes with $25 \mathrm{mg}$ of ENVI-Carb and $50 \mu \mathrm{L}$ of acetic acid, and the solutions were mixed by vortexing for $30 \mathrm{~s}$. After centrifugation at $1600 \times g$ for $15 \mathrm{~min}$, the extracts were dried under a nitrogen stream. The residue was then re-dissolved in $100 \mu \mathrm{l}$ of $100 \mathrm{mM}$ benzyl bromide acetone containing the recovery performance standard

${ }^{13} \mathrm{C}_{5}$-PFNA (1 ng) for 1 hour at $80{ }^{\circ} \mathrm{C}$ and transferred to an autosampler vial. Extracts were analyzed using gas chromatography-mass spectrometry (Agilent 6890GC/5973MSD, Agilent Technologies Japan, Ltd., Tokyo, Japan) in electron impact ionization mode using single ion monitoring. PFCA benzyl esters were separated on a DB-5MS column (30 m length, $0.25 \mathrm{~mm}$ i.d., $1 \mu \mathrm{m}$ film thickness) with a helium carrier gas. Split-less injections $(1 \mu \mathrm{l})$ were performed with the injector set at $220{ }^{\circ} \mathrm{C}$, and the split was opened after $1.5 \mathrm{~min}$. The initial oven temperature was $70{ }^{\circ} \mathrm{C}$ for $2 \mathrm{~min}$, ramped at $20{ }^{\circ} \mathrm{C} \min ^{-1}$ to $100 \mathrm{C}^{\circ}$, and then at $30{ }^{\circ} \mathrm{C} \min ^{-1}$ to $280{ }^{\circ} \mathrm{C}$. Ion fragments $\left([\mathrm{M}]^{+}\right)$were monitored and used as quantification ions (Table 2).

Instrumental detection limits (IDL) were defined as the mass of analyte producing a peak with a signal-to-noise ratio of 3 , and ranged from $1 \mathrm{pg}$ (PFTeDA) to $0.25 \mathrm{pg}$ (other PFCAs) (Table 2). Since blank samples (0.5 mL distilled water) contain no detectable concentrations, the method detection limits (MDL) value was considered to be equal to the IDL corresponding to $0.2 \mathrm{ng} \mathrm{mL}^{-1}$ for PFTeDA and $0.025 \mathrm{ng} \mathrm{mL}^{-1}$ for other PFCAs (Table 2).

\subsection{Quality assurance}

Quantification was performed using an internal standard method with the external 
159 standards dissolved in $10 \%$ methanol in water. ${ }^{13} \mathrm{C}_{4}$-PFOA was used as the internal 160 standard for PFCAs. ${ }^{13} \mathrm{C}_{5}$-PFNA was used to calculate a recovery rate of ${ }^{13} \mathrm{C}_{4}$-PFOA. All samples were quantified using a seven-point calibration curve with a relative standard deviation (RSD) of the relative response factors $<15 \%$ for all compounds. The recoveries were evaluated by five replicate fortifications (fortified by 10 times the original concentration of serum) of a human serum sample with low contamination (Table 2). The procedural blank levels were evaluated in duplicate for 11 samples each using $0.5 \mathrm{~mL}$ distilled water.

Using the above method, we reanalyzed 361 samples originally tested in a previous study by HPLC-MS/MS (Harada et al., 2010; Kärrman et al., 2009). The reanalyzed samples showed $5.14 \pm 11.60 \mathrm{ng} \mathrm{mL}^{-1}$ for PFOA, which equates to $101.7 \%$ of the levels obtained in the previous study $\left(5.05 \pm 11.16 \mathrm{ng} \mathrm{mL}{ }^{-1}, p=0.478\right.$ by paired $t$-test $)$. Pearson's correlation coefficient, $r$ and slope were 0.9882 and 1.128 , respectively $(p<0.0001)$. Levels (mean \pm SD) of PFHpA, PFNA, PFDA and PFUnDA in Osaka in 2004 were also confirmed in this study (HPLC-MS/MS vs GC-MS: $0.26 \pm 0.14 \mathrm{ng} \mathrm{mL}^{-1}$ vs $0.24 \pm 0.09 \mathrm{ng}$ $\mathrm{mL}^{-1}, 6.68 \pm 1.78 \mathrm{ng} \mathrm{mL}^{-1}$ vs $6.16 \pm 1.91 \mathrm{ng} \mathrm{mL}^{-1}, 2.55 \pm 0.99 \mathrm{ng} \mathrm{mL}^{-1}$ vs $2.74 \pm 1.32 \mathrm{ng}$ $\mathrm{mL}^{-1}, 5.80 \pm 2.13 \mathrm{ng} \mathrm{mL} \mathrm{L}^{-1}$ vs $5.12 \pm 2.69 \mathrm{ng} \mathrm{mL}^{-1}$, respectively; $p>0.05$ by paired $t$-test). RSDs of difference between methods were $33.1 \%, 9.8 \%, 13.6 \%$ and $11.5 \%$ for PFHpA, PFNA, PFDA and PFUnDA, respectively and average RSD was $17.0 \%$.

To assess potential interlaboratory difference in analysis, NIST standard reference material (SRM) 1957 was analyzed (Table 2). The values from PFHpA to PFUnDA were comparable to those from interlaboratory comparison exercises (Lindstrom et al., 2009; Keller et al., 2010).

Mean recovery rate (RSD) of ${ }^{13} \mathrm{C}_{4}$-PFOA in 521 samples was $96.5 \%$ (8.8\%). To 
evaluate possible matrix effect in serum sample, we further analyzed 100 samples extracts fortified with $1 \mathrm{ng}$ of PFHpA, PFNA, PFDA, PFUnDA, PFDoDA and PFTrDA standards. Recoveries of fortified standards were $98.7 \%, 104.6 \%, 102.0 \%, 97.2 \%$, 102.2\% and $96.3 \%$ for PFHpA, PFNA, PFDA, PFUnDA, PFDoDA and PFTrDA, respectively. It is therefore considered that there was no substantial suppression or enhancement of target ions, if any.

\subsection{Statistical analysis}

All statistical analyses were carried out using the JMP software (Version 4; SAS Institute Inc., Cary, NC). Values of $p<0.05$ were considered to indicate statistical significance. Concentrations of less than the detection limit were all approximated to 'half of detection limit' for statistical analyses. Serum levels of PFCAs were assumed to distribute lognormally because the serum levels of PFCAs in the samples displayed right-skewed patterns and geometric means were comparable to medians. Statistical analyses were conducted after logarithmic transformation of the serum concentrations.

Differences between mean values were tested by Tukey-Kramer's honestly significant difference (HSD) test after ANOVA. Correlation was tested by Spearman's rank correlation coefficient $(\rho)$. Factor analysis was used to transform a number of contaminants into a smaller number of potential factors of sources. Factor analysis was conducted via correlation matrix. In essence, the factor analysis is a model which presumes the existence of a smaller set of factors that can reproduce exactly the correlation in the larger set of variable. To achieve this goal, the linier combinations of factors (i.e., principal component) will be generated in such a manner that each 
composite variate will account a smaller portion of the total variation i.e., variance.

208 Eigenvalues of a principal component is a measure how much this principal component can account for the variation and eigenvector indicates an associated set of coefficients with a principal component for each factor. Eigenvectors were employed through the analysis when eigenvalues were close to or greater than 1 which means its eigenvector can account the equivalent of one or more original variables. Normalized varimax rotation (an orthogonal rotation of the factor axes) was applied to these eigenvectors to simplify them into a few variables with high correlations.

\section{Results}

\subsection{Temporal changes in PFCA concentrations in Japan}

The descriptive statistics for PFCAs are presented in Table 3. Most samples contained PFOA, PFNA, PFDA, PFUnDA and PFTrDA at both time points. No samples contained PFHxA and PFTeDA at concentrations above MDL. PFHpA levels were significantly decreased in all sampling sites in Japan between 2002/2004 and 2008/2009 ( $\mathrm{p}<0.05$ by Student's $t$-test). PFOA was relatively high in Osaka and Kyoto although levels of this compound nevertheless significantly decreased in this period $(\mathrm{p}<0.05$ by Student's $t$-test). In Sendai and Takayama, PFOA levels also decreased but this difference was not statistically significant. In contrast, PFCAs longer than PFOA showed significant increases in Sendai, Takayama and Kyoto with few exceptions. Among these PFCAs, PFUnDA was the predominant component, followed by PFNA, PFDA, PFTrDA and PFDoDA. These odd-numbered PFCAs (i.e. PFUnDA, PFNA and PFTrDA) were detected at higher concentrations than neighboring, even-numbered PFCAs (PFDA and PFDoDA). 
In Osaka, levels of PFNA, PFDA and PFUnDA, as with PFOA, significantly decreased from 2004 to 2008. PFDoDA and PFTrDA levels did not change. Among four levels than Sendai and Takayama ( $\mathrm{p}<0.05$ by Tukey's HSD test) but PFUnDA, PFDoDA and PFTrDA showed no regional differences ( $\mathrm{p}>0.05$ by ANOVA).

As a consequence of the increase in long-chain PFCAs, the proportion of PFOA in the total PFCA content became less than 50\% in all locations except Osaka.

\subsection{Temporal trends in the serum concentrations of PFCAs in Korea}

The PFCA concentrations in the serum samples collected in Busan and Seoul between 1994 and 2008 are shown in Table 4. As is the case with Japan, PFOA, PFNA, PFDA, PFUnDA and PFTrDA were frequently detected in 2007/2008. PFHxA and PFTeDA were not detected in any samples at concentrations above MDL. In agreement with the previous report by Harada et al. (2010), PFOA levels were stable from 1994 to 2008 in Busan and Seoul ( $p>0.05$ by ANOVA). In contrast, odd-numbered PFCAs (PFNA, PFUnDA and PFTrDA) were significantly increased during this period $(\mathrm{p}<0.05$ by Tukey's HSD test or Student's $t$-test). The PFCA levels had the following order of prevalence in 1994: PFOA $>$ PFNA PFUnDA $>$ PFDA $>$ PFTrDA $>$ PFHpA PFDoDA. However, by 2007/2008 the order had changed to: PFOA $>$ PFUnDA $>$ PFNA $>$ PFDA $\sim$ PFTrDA $>$ PFDoDA $>$ PFHpA. Between 1994 and 2007/2008, total PFCA levels were significantly increased by 1.31- and 1.53-fold in Busan and Seoul, respectively ( $\mathrm{p}<0.05$ by Tukey's HSD test or Student's $t$-test). 
by Student's $t$-test).

256

\subsection{PFCAs concentrations in Hanoi, Vietnam in 2008-2009}

PFOA, PFNA, PFDA and PFUnDA were detected in all samples, and PFDoDA and

PFTrDA were also detected, albeit less frequently (Table 5). PFHxA, PFHpA and

PFTeDA were not detected in any samples from Hanoi. The concentration of PFUnDA

PFDoDA. The proportion of PFOA relative to total PFCAs was only $12.9 \%$.

\subsection{Correlations among PFCA levels and factor analysis}

Correlation coefficients among PFCAs in 521 samples are listed in Table 6. PFHpA

significantly correlated with PFNA and PFDA ( $\rho$ coefficient $>0.5$ ) but was less well correlated with PFUnDA, PFDoDA and PFTrDA. In general, PFCA concentrations indicated a strong correlation between PFCAs of similar (i.e. adjacent) chain length.

To delineate potential patterns in the data, PFCA concentrations were examined using factor analysis. The contributions of factors 1 and 2 to the total variance were 49.72\% and $19.40 \%$ (with an eigenvalue $>1$ ), respectively (Table 7). After varimax rotation, the first factor indicated a higher eigenvector for longer-chain PFCAs than PFNA. The second factor had a more positive eigenvector for shorter-chain PFCAs than PFDA. Since there is a point source of PFCAs in both Osaka and Kyoto, we evaluated whether this predominant source may perturb the results of the factor analysis. among PFCAs with changes in eigenvalues being less than 5\% (data not shown), 
279 indicating that the dominant point source had no substantial influence on the 280 interpretation of factor 1 and factor 2.

281 Factor 1 is characterized by PFUnDA dominance (factor loading: 0.858) and another 282 by PFOA dominance (0.819), respectively. This characteristic pattern indicates 283 fingerprints of PFCAs sources in Asia. Temporal transition of factor scores is 284 demonstrated by score plots shown in Supplemental Fig. 1. In sampling sites in Japan and Korea (except for Osaka), centers of score plot moved rightwards and downwards, indicating that the factor 1 score increased and factor 2 score decreased during these periods. Mean factor scores of each sampling site are also shown in Table 7. In Japan, factor 1 scores significantly increased from 2002/2003 to 2008/2009 ( $p<0.05$ by Student's $t$-test), except for Osaka which already had a high factor 1 score $(0.92)$ in 2004. This increase in factor 1 scores was also observed in Busan and Seoul from 1994 to $2007 / 2008$ ( $p<0.05$ by Tukey's HSD test or Student's $t$-test). Although the factor 1 score in Hanoi was lower than those in other sites in 2007-2009, it surpassed scores in Sendai and Kyoto in 2002/2003 and in Busan and Seoul in 1994. Contrary to factor 1, factor 2 scores in all sampling sites in Japan significantly declined between 2002/2004 and 2008/2009 ( $<<0.05$ by Student's $t$-test) and also in Busan and Seoul from 1994 to 2007/2008 ( $<<0.05$ by Tukey's HSD test or Student's $t$-test). Factor 2 in Hanoi was the lowest among all sampling sites.

\section{Discussion}

In the present study, we uncovered two major fingerprints (factor 1 and factor 2) by 
with residual PFDoDA and PFDA, which can correspond to factor 1. Even in populations exposed to low levels of PFOA, notably Hanoi, PFUnDA showed substantial serum levels. Moreover, levels of those PFCAs with longer chain lengths than PFOA were significantly elevated in Japan and Korea in recent years. In the late-2000s, consequently, long-chain PFCA levels exceeded PFOA levels in most sampling sites. This finding suggests an emergence of specific sources of exposure in East Asia.

In several countries, serum PFOA has reportedly decreased (Harada et al., 2010; Olsen et al., 2008). In contrast, PFCAs of longer chain lengths than PFOA were frequently detected in serum samples in this study. Total levels of long-chain PFCAs were comparable to or greater than PFOA levels (except in Osaka) and showed trends towards increases in Japan and Korea. Correlation between PFOA and long-chain PFCAs was not strong which suggests that the sources of long-chain PFCA contamination have different exposure route than PFOA. Indeed, factor analysis demonstrated two major factors as sources of PFCAs. The first factor had loading on longer-chain PFCAs than PFOA and the second factor on PFHpA, PFOA and PFNA. Temporal trends of these factors were opposite and contamination derived from factor 1 might be expected to emerge in around a decade. This transition of factor scores was similar in Japan, Korea and Hanoi. Contamination derived from factor 1 may have been prevailing in East Asian countries.

Among long-chain PFCAs, odd-numbered PFCAs accounted for the major proportion. Serum or blood levels of PFCAs reported from populations in China, Sri Lanka, Australia, Norway, Sweden, Denmark, Poland, Belgium, Spain and USA are summarized in Table 8 (Ericson et al., 2007; Falandysz et al., 2006; Guruge et al., 2005; 
Haug et al., 2009; Joensen et al., 2009; Kärrman et al., 2006; Kuklenyik et al., 2004; Pan et al., 2010; Roosens et al., 2010; Toms et al., 2009). The PFCA composition in our current study, which was characterized by a large proportion of PFUnA, was apparently different from Western countries (Table 8). Although PFOA levels in these countries were comparable, long-chain PFCAs were not major components in Western countries, except for Antwerp, Belgium and Atlanta, USA. Therefore, this composition can be considered as a clear fingerprint for East Asian countries and is implicated in the origination of factor 1.

However, their source remains unclear due to insufficient monitoring data of PFCAs. Interestingly, a review by Prevedouros et al. (2006) indicated that PFNA has been manufactured in Japan via oxidation of fluorotelomer olefins together with PFUnDA and PFTrDA. Industrial application of these odd-numbered PFCAs, namely Surflon S-111, might contribute to the East Asian-specific pattern of serum body burdens. The contaminants.

In this study, there was a limitation in chemical analysis. ${ }^{13} \mathrm{C}_{4}$-PFOA was used for internal standard for PFCAs $\left(\mathrm{C}_{7}-\mathrm{C}_{14}\right)$. Chemical properties of PFCAs may, however, be different even though they have similar structures. Matrix effects also might affect quantification of PFCAs other than PFOA. Thus it is logically possible that recovery rates of ${ }^{13} \mathrm{C}_{4}$-PFOA might be extensively deviated from those of other PFCAs. Neverthelss, such a possibility is unlikely because recovery rates of PFCAs were higher than $90 \%$ and RSD were within $10 \%$, indicating that there was no substantial difference in recoveries among PFCAs in this method. Furthermore, a good agreement of results 
351

352

353

354

355

356

357

358

359

360

361

362

363

364

365

366

367

368

369

370

in SRM analysis by interlaboratory comparisons assured that our analytical method in this study is sound. Collectively, these findings consistently support that analytical method in this study was sufficiently qualified.

Recent epidemiological investigations have raised concern regarding developmental effects of PFOA on children (Steenland et al., 2010). In contrast, few studies have been conducted on the effects of PFCAs of different chain length. Even though PFCAs have similar structure, their chemical properties and biological activity are likely different. In several in vitro studies, long-chain PFCAs caused biological responses at lower doses than PFOA (Liao et al., 2009; Matsubara et al., 2006; Upham et al., 1998). The toxicokinetics of long-chain PFCAs are also unclear, especially in humans. These uncertainties necessitate more comprehensive toxicological studies on PFCAs.

\section{Acknowledgments}

We are grateful to Dr. Anna Kärrman (Örebro University, Sweden) for valuable instructions for quality assurance. This study was mainly supported by Special Coordination Funds for Promoting Science and Technology (No. 1300001) sponsored by the Japan Science and Technology Agency, and a Grant-in-Aid for Health Sciences Research from the Ministry of Health, Labour and Welfare of Japan (H21-Food-003). The authors have no financial conflicts of interest. 


\section{References}

Ericson, I., Gomez, M., Nadal, M., van Bavel, B., Lindstrom, G., Domingo, J.L., 2007. Perfluorinated chemicals in blood of residents in Catalonia (Spain) in relation to age and gender: A pilot study. Environ Int.

Falandysz, J., Taniyasu, S., Gulkowska, A., Yamashita, N., Schulte-Oehlmann, U., 2006. Is fish a major source of fluorinated surfactants and repellents in humans living on the Baltic Coast? Environ Sci Technol 40, 748-751.

Furdui, V.I., Helm, P.A., Crozier, P.W., Lucaciu, C., Reiner, E.J., Marvin, C.H., Whittle, M.D., Mabury, S.A., Tomy, G., 2008. Temporal trends of perfluoroalkyl compounds with isomer analysis in lake trout from Lake Ontario (1974-2004). Environ. Sci. Technol. 42, 4739-4744.

Guruge, K.S., Taniyasu, S., Yamashita, N., Wijeratna, S., Mohotti, K.M., Seneviratne, H.R., Kannan, K., Yamanaka, N., Miyazaki, S., 2005. Perfluorinated organic compounds in human blood serum and seminal plasma: a study of urban and rural tea worker populations in Sri Lanka. J Environ Monit 7, 371-377.

Harada, K., Koizumi, A., Saito, N., Inoue, K., Yoshinaga, T., Date, C., Fujii, S., Hachiya, N., Hirosawa, I., Koda, S., Kusaka, Y., Murata, K., Omae, K., Shimbo, S., Takenaka, K., Takeshita, T., Todoriki, H., Wada, Y., Watanabe, T., Ikeda, M., 2007. Historical and geographical aspects of the increasing perfluorooctanoate and perfluorooctane sulfonate contamination in human serum in Japan. Chemosphere 66, 293-301.

Harada, K., Saito, N., Inoue, K., Yoshinaga, T., Watanabe, T., Sasaki, S., Kamiyama, S., Koizumi, A., 2004. The influence of time, sex and geographic factors on levels of perfluorooctane sulfonate and perfluorooctanoate in human serum over the 
last 25 years. J Occup Health 46, 141-147.

Harada, K.H., Koizumi, A., 2009. Environmental and biological monitoring of persistent fluorinated compounds in Japan and their toxicities. Environ Health Prev Med 14, 7-19.

Harada, K.H., Yang, H.R., Moon, C.S., Hung, N.N., Hitomi, T., Inoue, K., Niisoe, T., Watanabe, T., Kamiyama, S., Takenaka, K., Kim, M.Y., Watanabe, K., Takasuga, T., Koizumi, A., 2010. Levels of perfluorooctane sulfonate and perfluorooctanoic acid in female serum samples from Japan in 2008, Korea in 1994-2008 and Vietnam in 2007-2008. Chemosphere 79, 314-319.

Haug, L.S., Thomsen, C., Becher, G., 2009. Time trends and the influence of age and gender on serum concentrations of perfluorinated compounds in archived human samples. Environ. Sci. Technol. 43, 2131-2136.

Houde, M., Martin, J.W., Letcher, R.J., Solomon, K.R., Muir, D.C., 2006. Biological monitoring of polyfluoroalkyl substances: A review. Environ Sci Technol 40, 3463-3473.

Joensen, U.N., Bossi, R., Leffers, H., Jensen, A.A., Skakkebaek, N.E., Jorgensen, N., 2009. Do perfluoroalkyl compounds impair human semen quality? Environ Health Perspect 117, 923-927.

Kärrman, A., Harada, K.H., Inoue, K., Takasuga, T., Ohi, E., Koizumi, A., 2009. Relationship between dietary exposure and serum perfluorochemical (PFC) levels--a case study. Environ Int 35, 712-717.

Kärrman, A., van Bavel, B., Jarnberg, U., Hardell, L., Lindstrom, G., 2006. Perfluorinated chemicals in relation to other persistent organic pollutants in human blood. Chemosphere 64, 1582-1591. 
Kato, K., Calafat, A.M., Wong, L.Y., Wanigatunga, A.M., Caudill, S.P., Needham, L.L., 2009. Polyfluoroalkyl Compounds in Pooled Sera from Children Participating in the National Health and Nutrition Examination Survey 2001-2002. Environ. Sci. Technol. 43, 2641-2647.

Koizumi, A., Harada, K., Inoue, K., Hitomi, T., Yang, H.-R., Moon, C.-S., Wang, P., Hung, N., Watanabe, T., Shimbo, S., Ikeda, M., 2009. Past, present, and future of environmental specimen banks. Environmental Health and Preventive Medicine 14, 307-318.

Koizumi, A., Yoshinaga, T., Harada, K., Inoue, K., Morikawa, A., Muroi, J., Inoue, S., Eslami, B., Fujii, S., Fujimine, Y., Hachiya, N., Koda, S., Kusaka, Y., Murata, K., Nakatsuka, H., Omae, K., Saito, N., Shimbo, S., Takenaka, K., Takeshita, T., Todoriki, H., Wada, Y., Watanabe, T., Ikeda, M., 2005. Assessment of human exposure to polychlorinated biphenyls and polybrominated diphenyl ethers in Japan using archived samples from the early 1980s and mid-1990s. Environ Res 99, 31-39.

Kuklenyik, Z., Reich, J.A., Tully, J.S., Needham, L.L., Calafat, A.M., 2004. Automated solid-phase extraction and measurement of perfluorinated organic acids and amides in human serum and milk. Environ Sci Technol 38, 3698-3704.

Liao, C., Wang, T., Cui, L., Zhou, Q., Duan, S., Jiang, G., 2009. Changes in Synaptic Transmission, Calcium Current, and Neurite Growth by Perfluorinated Compounds Are Dependent on the Chain Length and Functional Group. Environmental Science \& Technology 43, 2099-2104.

Martin, J.W., Mabury, S.A., Solomon, K.R., Muir, D.C.G., 2003. Bioconcentration and tissue distribution of perfluorinated acids in rainbow trout (Oncorhynchus 
mykiss). Environmental Toxicology and Chemistry 22, 196-204.

444

Matsubara, E., Harada, K., Inoue, K., Koizumi, A., 2006. Effects of perfluorinated amphiphiles on backward swimming in Paramecium caudatum. Biochem Biophys Res Commun 339, 554-561.

Niisoe, T., Harada, K.H., Ishikawa, H., Koizumi, A., 2010. Long-term simulation of human exposure to atmospheric perfluorooctanoic acid (PFOA) and perfluorooctanoate (PFO) in the Osaka urban area, Japan. Environ Sci Technol $44,7852-7857$.

Olsen, G.W., Mair, D.C., Church, T.R., Ellefson, M.E., Reagen, W.K., Boyd, T.M., Herron, R.M., Medhdizadehkashi, Z., Nobiletti, J.B., Rios, J.A., Butenhoff, J.L., Zobel, L.R., 2008. Decline in perfluorooctanesulfonate and other polyfluoroalkyl chemicals in American Red Cross adult blood donors, 2000-2006. Environ Sci Technol 42, 4989-4995.

Pan, Y., Shi, Y., Wang, J., Cai, Y., Wu, Y., 2010. Concentrations of perfluorinated compounds in human blood from twelve cities in China. Environ Toxicol Chem $29,2695-2701$.

Powley, C.R., George, S.W., Ryan, T.W., Buck, R.C., 2005. Matrix effect-free analytical methods for determination of perfluorinated carboxylic acids in environmental matrixes. Anal Chem 77, 6353-6358.

Prevedouros, K., Cousins, I.T., Buck, R.C., Korzeniowski, S.H., 2006. Sources, fate and transport of perfluorocarboxylates. Environ Sci Technol 40, 32-44.

Renner, R., 2001. Scotchgard scotched - Following the fabric protector's slippery trail to a new class of pollutant. Sci Am 284, 18.

Roosens, L., D'Hollander, W., Bervoets, L., Reynders, H., Van Campenhout, K., 
Cornelis, C., Van Den Heuvel, R., Koppen, G., Covaci, A., 2010. Brominated flame retardants and perfluorinated chemicals, two groups of persistent contaminants in Belgian human blood and milk. Environ Pollut 158, 2546-2552.

Steenland, K., Fletcher, T., Savitz, D.A., 2010. Epidemiologic evidence on the health effects of perfluorooctanoic acid (PFOA). Environ Health Perspect 118, 1100-1108.

Toms, L.M., Calafat, A.M., Kato, K., Thompson, J., Harden, F., Hobson, P., Sjodin, A., Mueller, J.F., 2009. Polyfluoroalkyl chemicals in pooled blood serum from infants, children, and adults in Australia. Environ Sci Technol 43, 4194-4199.

Upham, B.L., Deocampo, N.D., Wurl, B., Trosko, J.E., 1998. Inhibition of gap junctional intercellular communication by perfluorinated fatty acids is dependent on the chain length of the fluorinated tail. Int J Cancer 78, 491-495. 


\section{$482 \quad$ Figure captions}

\section{Supplemental Fig. 1.}

484 Plot of first- and second factor scores of 521 samples in Osaka (A), Kyoto (B), 485 Takayama (C), Sendai (D), Busan (E) and Seoul and Hanoi (F). Overall, 50\% of the 486 values locate within the boundary circles for each sampling site and time period.

487

488

489 
Table 1

Study area and study population

\begin{tabular}{|c|c|c|c|c|c|c|c|}
\hline \multirow{3}{*}{ 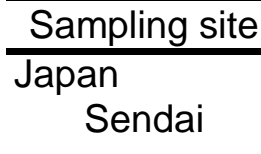 } & \multirow{3}{*}{$\begin{array}{c}\text { Population }\left(\times 10^{3}\right) \\
1,031\end{array}$} & \multirow{3}{*}{$\begin{array}{l}\text { Latitude and longitude } \\
38^{\circ} 17^{\prime} 04^{\prime \prime} \text { N } 140^{\circ} 55^{\prime} 46^{\prime \prime} \mathrm{E}\end{array}$} & \multirow{3}{*}{$\begin{array}{l}\text { Year } \\
2008\end{array}$} & \multicolumn{2}{|c|}{ n (\%female } & $\mathrm{Age}^{\mathrm{a}}$ & \multirow{2}{*}{ (range) } \\
\hline & & & & & & & \\
\hline & & & & 50 & $(100)$ & $37.5 \pm 9.44$ & $(21-53)$ \\
\hline & 1,023 & - & 2003 & 50 & $(100)$ & $36.6 \pm 10.1$ & $(20-59)$ \\
\hline \multirow[t]{2}{*}{ Takayama } & $94(65)^{b}$ & $36^{\circ} 08^{\prime} 13^{\prime \prime} \mathrm{N} 137^{\circ} 15^{\prime} 16^{\prime \prime} \mathrm{E}$ & 2008 & 50 & $(100)$ & $40.5 \pm 4.78$ & $(29-49)$ \\
\hline & 67 & - & 2003 & 50 & $(100)$ & $39.9 \pm 4.5$ & $(31-45)$ \\
\hline \multirow[t]{2}{*}{ Kyoto } & 1,466 & $35^{\circ} 01^{\prime} 18^{\prime \prime} \mathrm{N} 135^{\circ} 46^{\prime} 38^{\prime \prime} \mathrm{E}$ & 2009 & 30 & (50) & $33.2 \pm 14.7$ & $(21-68)$ \\
\hline & 1,469 & - & 2002 & 30 & (50) & $35.4 \pm 11.3$ & $(21-58)$ \\
\hline \multirow[t]{2}{*}{ Osaka } & 2,652 & $34^{\circ} 45^{\prime} 31^{\prime \prime} \mathrm{N} 135^{\circ} 31^{\prime} 52^{\prime \prime} \mathrm{E}$ & 2008 & 50 & $(100)$ & $45.9 \pm 8.92^{\mathrm{A}^{*}}$ & $(30-63)$ \\
\hline & 2,619 & - & 2004 & 10 & $(100)$ & $60.9 \pm 6.3^{\mathrm{B}}$ & $(49-69)$ \\
\hline \multicolumn{8}{|l|}{ Korea } \\
\hline \multirow[t]{3}{*}{ Busan } & 3,711 & $35^{\circ} 14^{\prime} 39^{\prime \prime} \mathrm{N} 129^{\circ} 05^{\prime} 54^{\prime \prime} \mathrm{E}$ & 2008 & 35 & $(100)$ & $40.1 \pm 6.44^{\mathrm{A}^{*}}$ & $(18-49)$ \\
\hline & 3,732 & - & 2000 & 30 & $(100)$ & $35.4 \pm 4.27^{\mathrm{B}}$ & $(28-45)$ \\
\hline & 3,961 & - & 1994 & 39 & $(100)$ & $42.3 \pm 4.65^{\mathrm{A}}$ & $(34-52)$ \\
\hline \multirow[t]{2}{*}{ Seoul } & 10,421 & $37^{\circ} 27^{\prime} 52^{\prime \prime}$ N 12701'56" E & 2007 & 36 & $(100)$ & $34.5 \pm 8.24$ & $(20-54)$ \\
\hline & 10,798 & - & 1994 & 24 & $(100)$ & $38.0 \pm 7.41$ & $(24-51)$ \\
\hline \multicolumn{8}{|l|}{ Vietnam } \\
\hline Hanoi & 6,232 & $21^{\circ} 00^{\prime} 08^{\prime \prime} \mathrm{N} 105^{\circ} 49^{\prime} 50^{\prime \prime} \mathrm{E}$ & 2007-2008 & 37 & $(100)$ & $30.2 \pm 5.76$ & $(20-40)$ \\
\hline
\end{tabular}

* Means of age with different letters differed significantly $(p<0.05$ by Tukey's HSD test). For example, the letters $A$ and $B$ indicate that the corresponding values differ significantly at $p<0.05$.

a Data are presented as mean \pm standard deviation.

b Takayama city merged with neighboring cities in 2005. Numbers in paretheses denote populations areas corresponding to those used in 2003. 
Table 2

Recovery, detection limits and QA for PFCA analysis in human serum samples

\begin{tabular}{|c|c|c|c|c|c|}
\hline Compound & $\begin{array}{l}\text { Quantification } \\
\text { (confirmation) }\end{array}$ & $\begin{array}{c}\text { Recovery and (reproducibility) } \\
\%(\mathrm{RSD} \%)^{\mathrm{a}}(\mathrm{n}=5)\end{array}$ & $\begin{array}{l}\text { Instrument detection } \\
\operatorname{limit}^{\mathrm{b}}(\mathrm{pg}) \\
\end{array}$ & $\begin{array}{c}\text { detection } \\
\text { limit }^{\mathrm{C}}\left(\mathrm{ng} \mathrm{mL^{-1 }}\right)\end{array}$ & $\begin{array}{l}\text { SRM1957 }^{\mathrm{d}} \\
\left(\mathrm{ng} \mathrm{mL}{ }^{-1}\right)\end{array}$ \\
\hline PFHXA & 404 (385) & $92.2(8.41)$ & 0.25 & 0.05 & $<0.05$ \\
\hline PFHpA & 454 (435) & $94.5(4.12)$ & 0.25 & 0.05 & 0.27 \\
\hline PFOA & 504 (485) & $101.7(6.99)$ & 0.25 & 0.05 & 4.77 \\
\hline${ }^{13} \mathrm{C}_{4}$ PFOA & 508 (489) & $102.8(5.47)$ & - & - & - \\
\hline PFNA & $554(535)$ & $97.4(7.61)$ & 0.25 & 0.05 & 0.96 \\
\hline${ }^{13} \mathrm{C}_{5}$ PFNA & $559(540)$ & - & - & - & - \\
\hline PFDA & $604(585)$ & $91.9(8.63)$ & 0.25 & 0.05 & 0.26 \\
\hline PFUnDA & 654 (635) & $94.1(7.22)$ & 0.25 & 0.05 & 0.16 \\
\hline PFDoDA & 704 (685) & $95.7(4.87)$ & 0.5 & 0.1 & $<0.1$ \\
\hline PFTrDA & 754 (735) & $98.6(9.41)$ & 0.5 & 0.1 & $<0.1$ \\
\hline PFTeDA & 785 (786) & $92.4(8.18)$ & 1 & 0.2 & $<0.2$ \\
\hline
\end{tabular}

${ }^{\mathrm{a}} \mathrm{RSD}$ : relative standard deviation

${ }^{b} 1 \mu l$ injection

${ }^{c} 0.5 \mathrm{~mL}$ serum sample

${ }^{\mathrm{d}} 0.5 \mathrm{~mL}$ serum sample of NIST SRM 1957 was analyzed. 
Table 3

Serum concentrations of PFCAs in Japan

\begin{tabular}{|c|c|c|c|c|c|c|c|c|c|c|c|}
\hline $\begin{array}{l}\text { Sampling } \\
\text { site }\end{array}$ & Year & $\mathrm{n}$ & & $\begin{array}{l}\text { Concentratic } \\
\text { PFHpA }\end{array}$ & $\begin{array}{c}\text { on }\left(\mathrm{ng} \mathrm{mL}^{-1}\right) \\
\text { PFOA }\end{array}$ & PFNA & PFDA & PFUnDA & PFDoDA & PFTrDA & $\Sigma$ PFCAs \\
\hline \multirow[t]{2}{*}{ Sendai } & 2008 & 50 & $\begin{array}{l}\text { GM(GSD) } \\
\text { range } \\
\text { detection\% }\end{array}$ & $\begin{array}{c}0.06(2.17)^{\star} \\
<0.05-0.37 \\
58\end{array}$ & $\begin{array}{c}2.44(1.56) \\
0.85-6.05 \\
100\end{array}$ & $\begin{array}{c}1.80(1.40)^{*}( \\
0.90-3.58 \\
100\end{array}$ & $\begin{array}{c}0.72(1.46)^{*} \\
0.31-1.58 \\
100\end{array}$ & $\begin{array}{c}{ }^{*} .00(1.59)^{*} \\
1.15-8.08 \\
100\end{array}$ & $\begin{array}{c}0.17(1.99)^{*} \\
<0.1-0.52 \\
82\end{array}$ & $\begin{array}{c}{ }^{*} 0.60(2.00)^{*} \\
<0.1-1.43 \\
96\end{array}$ & $\begin{array}{l}9.13(1.41)^{*} \\
3.81-17.52\end{array}$ \\
\hline & 2003 & 50 & $\begin{array}{l}\text { GM(GSD) } \\
\text { range } \\
\text { detection\% }\end{array}$ & $\begin{array}{c}0.15(3.75) \\
<0.05-1.25 \\
72\end{array}$ & $\begin{array}{c}2.65(1.61) \\
0.87-7.59 \\
100\end{array}$ & $\begin{array}{c}1.01(1.85) \\
0.21-4.94 \\
100\end{array}$ & $\begin{array}{c}0.52(1.71) \\
0.09-1.57 \\
100\end{array}$ & $\begin{array}{c}1.68(1.75) \\
0.32-5.70 \\
100\end{array}$ & $\begin{array}{c}0.10(1.85) \\
<0.1-0.37 \\
58\end{array}$ & $\begin{array}{c}0.31(2.12) \\
<0.1-1.13 \\
100\end{array}$ & $\begin{array}{l}6.92(1.51) \\
2.74-17.94\end{array}$ \\
\hline \multirow[t]{2}{*}{ Takayama } & 2008 & 50 & $\begin{array}{l}\text { GM(GSD) } \\
\text { range } \\
\text { detection\% }\end{array}$ & $\begin{array}{c}0.04(2.29)^{*} \\
<0.05-0.49 \\
38\end{array}$ & $\begin{array}{c}2.51(1.84) \\
0.82-11.25 \\
100\end{array}$ & $\begin{array}{c}1.78(1.42)^{\star} \\
1.01-4.50 \\
100\end{array}$ & $\begin{array}{c}0.85(1.51)^{*} \\
0.26-2.68 \\
100\end{array}$ & $\begin{array}{c}{ }^{3} 3.12(1.51) \\
1.28-7.13 \\
100\end{array}$ & $\begin{array}{c}0.20(2.15)^{*} \\
<0.1-0.61 \\
82\end{array}$ & $\begin{array}{c}0.60(2.66) \\
<0.1-2.46 \\
94\end{array}$ & $\begin{array}{l}9.87(1.39) \\
5.44-22.09\end{array}$ \\
\hline & 2003 & 50 & $\begin{array}{l}\text { GM(GSD) } \\
\text { range } \\
\text { detection\% }\end{array}$ & $\begin{array}{c}0.11(2.35) \\
<0.05-1.72 \\
88\end{array}$ & $\begin{array}{c}3.19(1.62) \\
1.36-20.28 \\
100\end{array}$ & $\begin{array}{c}1.30(1.73) \\
0.64-9.88 \\
100\end{array}$ & $\begin{array}{c}0.65(1.63) \\
0.18-2.26 \\
100\end{array}$ & $\begin{array}{c}2.74(1.60) \\
0.77-7.81 \\
100\end{array}$ & $\begin{array}{c}0.14(1.88) \\
<0.1-0.51 \\
80\end{array}$ & $\begin{array}{c}0.55(1.72) \\
0.16-1.98 \\
100\end{array}$ & $\begin{array}{l}9.18(1.49) \\
4.49-37.04\end{array}$ \\
\hline \multirow[t]{2}{*}{ Kyoto } & 2009 & 30 & $\begin{array}{l}\text { GM(GSD) } \\
\text { range } \\
\text { detection\% }\end{array}$ & $\begin{array}{c}0.11(1.98)^{*} \\
<0.05-0.31 \\
96.7\end{array}$ & $\begin{array}{c}5.28(1.57)^{*} \\
2.60-16.52 \\
100\end{array}$ & $\begin{array}{c}2.78(1.42)^{*} \\
1.34-4.40 \\
100\end{array}$ & $\begin{array}{c}1.10(1.45) \\
0.60-2.25 \\
100\end{array}$ & $\begin{array}{c}3.20(1.64)^{*} \\
1.20-11.26 \\
100\end{array}$ & $\begin{array}{c}{ }^{*} 0.24(1.87)^{*} \\
<0.1-0.99 \\
93.3\end{array}$ & $\begin{array}{c}{ }^{*} 0.45(1.57)^{*} \\
0.22-1.15 \\
100\end{array}$ & $\begin{array}{c}13.67(1.42) \\
6.60-26.81\end{array}$ \\
\hline & 2002 & 30 & $\begin{array}{c}\text { GM(GSD) } \\
\text { range } \\
\text { detection\% }\end{array}$ & $\begin{array}{c}0.23(1.89) \\
0.08-1.25 \\
100\end{array}$ & $\begin{array}{c}7.12(1.54) \\
2.69-19.64 \\
100\end{array}$ & $\begin{array}{c}2.09(1.67) \\
0.81-5.37 \\
100\end{array}$ & $\begin{array}{c}0.91(1.66) \\
0.35-2.54 \\
100\end{array}$ & $\begin{array}{c}1.89(1.65) \\
0.72-5.44 \\
100\end{array}$ & $\begin{array}{c}0.12(2.04) \\
<0.1-0.37 \\
66.7\end{array}$ & $\begin{array}{c}0.31(1.83) \\
<0.1-1.00 \\
96.7\end{array}$ & $\begin{array}{l}12.98(1.52) \\
5.38-33.75\end{array}$ \\
\hline \multirow[t]{2}{*}{ Osaka } & 2008 & 50 & $\begin{array}{l}\text { GM(GSD) } \\
\text { range } \\
\text { detection\% }\end{array}$ & $\begin{array}{c}0.07(3.11)^{\star} \\
<0.05-1.11 \\
48\end{array}$ & $\begin{array}{c}13.46(1.79)^{*} \\
5.59-201.68 \\
100\end{array}$ & $\begin{array}{c}3.54(1.62)^{*} \\
0.85-14.57 \\
100\end{array}$ & $\begin{array}{c}1.11(1.60)^{*} \\
0.36-2.80 \\
100\end{array}$ & $\begin{array}{c}\text { *3.05(1.73)* } \\
1.01-8.79 \\
100\end{array}$ & $\begin{array}{c}{ }^{*} 0.16(2.55) \\
<0.1-0.75 \\
68\end{array}$ & $\begin{array}{c}0.52(2.62) \\
<0.1-1.95 \\
94\end{array}$ & $\begin{array}{c}23.08(1.64)^{\star} \\
10.77-220.07\end{array}$ \\
\hline & 2004 & 10 & $\begin{array}{l}\text { GM(GSD) } \\
\text { range } \\
\text { detection\% }\end{array}$ & $\begin{array}{c}0.21(2.00) \\
0.05-0.45 \\
100\end{array}$ & $\begin{array}{c}29.54(1.29) \\
20.60-45.20 \\
100\end{array}$ & $\begin{array}{c}6.41(1.38) \\
3.07-9.22 \\
100\end{array}$ & $\begin{array}{c}2.38(1.48) \\
1.41-4.17 \\
100\end{array}$ & $\begin{array}{c}5.45(1.46) \\
3.19-9.01 \\
100\end{array}$ & $\begin{array}{c}0.25(2.28) \\
<0.1-0.51 \\
90\end{array}$ & $\begin{array}{c}0.44(2.40) \\
<0.1-1.02 \\
90\end{array}$ & $\begin{array}{l}45.42(1.27) \\
31.67-65.57\end{array}$ \\
\hline
\end{tabular}

GM: Geometric mean; GSD: Geometric standard deviation

* GMs between time points are significantly different in each sampling site ( $p<0.05$ by Student's $t$ test after log transformation). 
Table 4

Serum concentrations of PFCAs in Korea

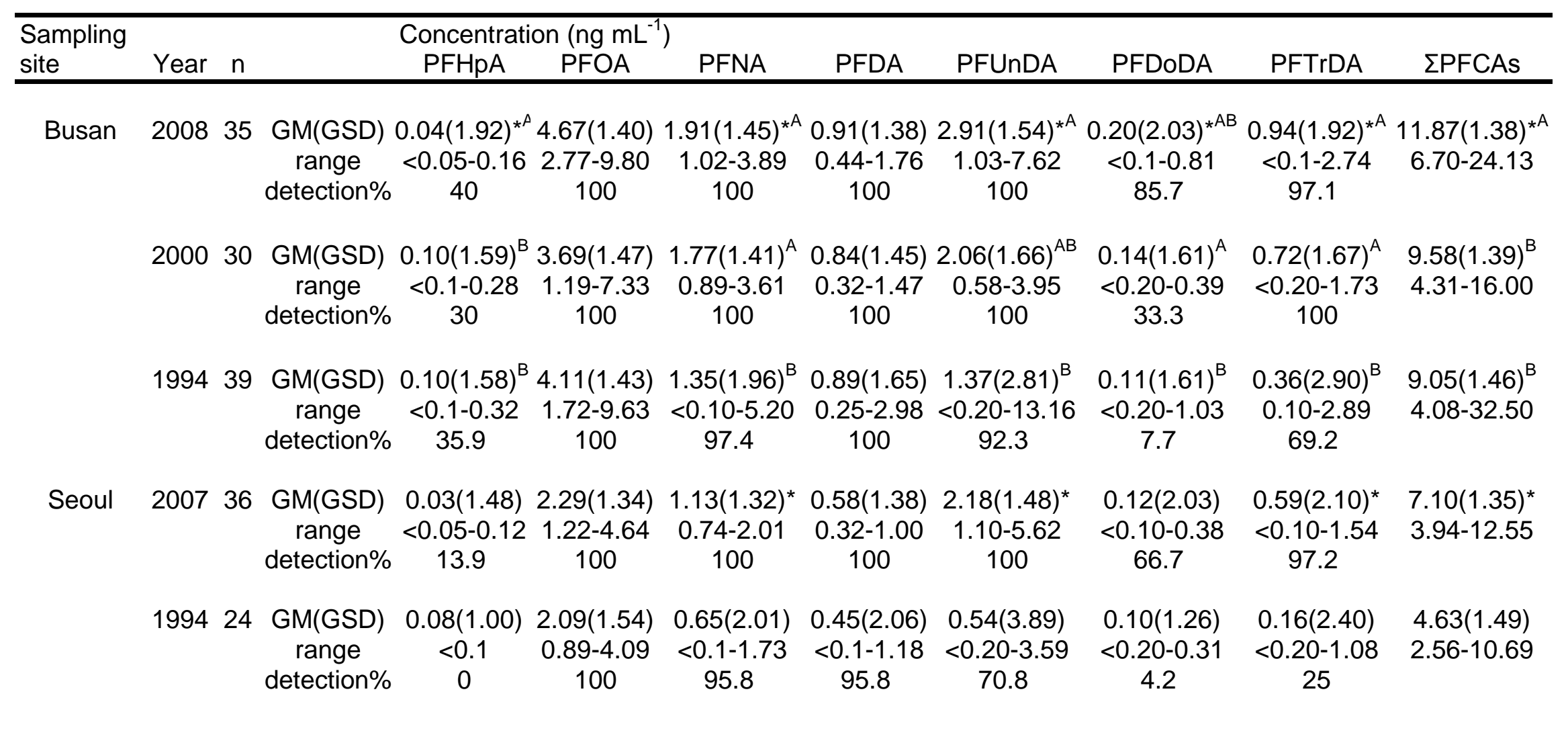

GM: Geometric mean; GSD: Geometric standard deviation

* GMs among different time points are significantly different in each sampling sites $(p<0.05$ by Student's $t$ test or Tukey's HSD test after log transformation). Alphabetic suffix was used for comparisons among three groups. For example, the letters $A$ and $B$ indicate that the corresponding values differ significantly at $p<0.05$., while $A$ and $A B$ or $A B$ and $B$ indicated that the corresponding values do 
Table 5

Serum concentrations of PFCAs in Hanoi, Vietnam

\begin{tabular}{|c|c|c|c|c|c|c|c|c|c|c|c|}
\hline Sampling & & & & Concentrat & tion (ng mL & & & & & & \\
\hline & Year & $\mathrm{n}$ & & PFHpA & PFOA & PFNA & PFDA & PFUnDA & PFDoDA & PFTrDA & $\Sigma$ PFCAs \\
\hline Hanoi & $\begin{array}{r}2007- \\
2008\end{array}$ & 37 & $\begin{array}{l}\text { GM(GSD) } \\
\text { range } \\
\text { detection\% }\end{array}$ & $\begin{array}{c}0.03(1.00) \\
<0.05 \\
0\end{array}$ & $\begin{array}{c}0.61(1.55) \\
0.20-1.43 \\
100\end{array}$ & $\begin{array}{c}0.89(1.47) \\
0.35-1.65 \\
100\end{array}$ & $\begin{array}{c}0.82(1.67) \\
0.19-2.03 \\
100\end{array}$ & $\begin{array}{c}1.55(1.53) \\
0.57-3.95 \\
100\end{array}$ & $\begin{array}{c}0.09(1.85) \\
<0.10-0.26 \\
51.4\end{array}$ & $\begin{array}{c}0.36(3.38) \\
<0.10-1.99 \\
86.5\end{array}$ & $\begin{array}{l}4.73(1.38) \\
2.58-9.43\end{array}$ \\
\hline
\end{tabular}

GM: Geometric mean; GSD: Geometric standard deviation 
Table 6

Correlation between different chain length PFCAs

\begin{tabular}{lll}
\hline Combination $\rho$ & $p$ value
\end{tabular}

\begin{tabular}{llll}
\hline PFOA & PFHpA & 0.398 & $<0.001$ \\
\hline PFNA & PFHpA & 0.223 & $<0.001$ \\
PFNA & PFOA & 0.734 & $<0.001$ \\
\hline PFDA & PFHpA & 0.165 & $<0.001$ \\
PFDA & PFOA & 0.534 & $<0.001$ \\
PFDA & PFNA & 0.727 & $<0.001$ \\
\hline PFUnDA & PFHpA & 0.019 & 0.660 \\
PFUnDA & PFOA & 0.323 & $<0.001$ \\
PFUnDA & PFNA & 0.646 & $<0.001$ \\
PFUnDA & PFDA & 0.689 & $<0.001$ \\
\hline PFDoDA & PFHpA & 0.055 & 0.208 \\
PFDoDA & PFOA & 0.235 & $<0.001$ \\
PFDoDA & PFNA & 0.462 & $<0.001$ \\
PFDoDA & PFDA & 0.563 & $<0.001$ \\
PFDoDA & PFUnDA & 0.740 & $<0.001$ \\
\hline PFTrDA & PFHpA & -0.117 & 0.008 \\
PFTrDA & PFOA & 0.063 & 0.151 \\
PFTrDA & PFNA & 0.264 & $<0.001$ \\
PFTrDA & PFDA & 0.360 & $<0.001$ \\
PFTrDA & PFUnDA & 0.552 & $<0.001$ \\
PFTrDA & PFDoDA & 0.471 & $<0.001$ \\
\hline P: Spearman's rank correlation coefficient
\end{tabular}


Table 7

Factor analysis among PFCAs

\begin{tabular}{ccccc}
\hline & Initial solution & \multicolumn{3}{c}{ Varimax rotated } \\
& $\mathrm{F} 1$ & $\mathrm{~F} 2$ & $\mathrm{~F} 1$ & $\mathrm{~F} 2$ \\
\hline Eigenvalue & 3.48 & 1.36 & & \\
Contribution (\%) & 49.72 & 19.40 & & \\
& & & & \\
Eigenvector & & & & \\
PFHpA & 0.092 & 0.618 & -0.198 & 0.713 \\
PFOA & 0.365 & 0.480 & 0.327 & 0.819 \\
PFNA & 0.474 & 0.179 & 0.673 & 0.610 \\
PFDA & 0.469 & 0.036 & 0.745 & 0.459 \\
PFUnDA & 0.446 & -0.230 & 0.858 & 0.168 \\
PFDoDA & 0.374 & -0.266 & 0.760 & 0.066 \\
PFTrDA & 0.274 & -0.481 & 0.719 & -0.244 \\
\hline Factor score (mean \pm standard deviation) & & \\
Sendai & 2008 & & $0.31 \pm 0.78^{\star}$ & $-0.41 \pm 0.67^{\star}$ \\
& 2003 & & $-0.84 \pm 0.90$ & $0.17 \pm 0.92$ \\
Takayama & 2008 & & $0.50 \pm 0.67^{\star}$ & $-0.49 \pm 0.85^{\star}$ \\
& 2003 & & $-0.10 \pm 0.76$ & $0.02 \pm 0.81$ \\
Kyoto & 2009 & & $0.44 \pm 0.68^{*}$ & $0.68 \pm 0.52^{*}$ \\
& 2002 & & $-0.46 \pm 0.85$ & $1.29 \pm 0.50$ \\
Osaka & 2008 & & $0.91 \pm 1.03$ & $1.17 \pm 0.78^{\star}$ \\
& 2004 & & $0.92 \pm 0.71$ & $2.42 \pm 0.48$ \\
Busan & 2008 & & $0.68 \pm 0.67^{\dagger \mathrm{A}}$ & $-0.28 \pm 0.56^{\dagger \mathrm{A}}$ \\
& 2000 & & $0.06 \pm 0.61^{\mathrm{B}}$ & $0.15 \pm 0.46^{\mathrm{A}}$ \\
& 1994 & & $-0.48 \pm 0.95^{\mathrm{C}}$ & $0.42 \pm 0.63^{\mathrm{B}}$ \\
Seoul & 2007 & & $0.02 \pm 0.69^{\dagger \mathrm{A}}$ & $-0.92 \pm 0.36^{\dagger \mathrm{A}}$ \\
& 1994 & & $-1.49 \pm 0.90^{\mathrm{B}}$ & $-0.22 \pm 0.48^{\mathrm{B}}$ \\
Hanoi & $2007-$ & & $-0.27 \pm 0.74$ & $-1.48 \pm 0.65$ \\
& 2008 & & & \\
\hline
\end{tabular}

F1: 1st factor; F2: 2nd factor

${ }^{*}$ Means between time points are significantly different $(p<0.05$ by Student's t test)

† Means among different time points are significantly different ( $p<0.05$ by Student's t test or Tukey's HSD test). For example, the letters $A$ and $B$ indicate that the corresponding values differ significantly at $p<0.05$., while $A$ and $A$ or $B$ and $B$ indicated that the corresponding values do not differ significantly. 
Table 8

Comparison of serum or whole blood concentrations of PFCAs with reported data

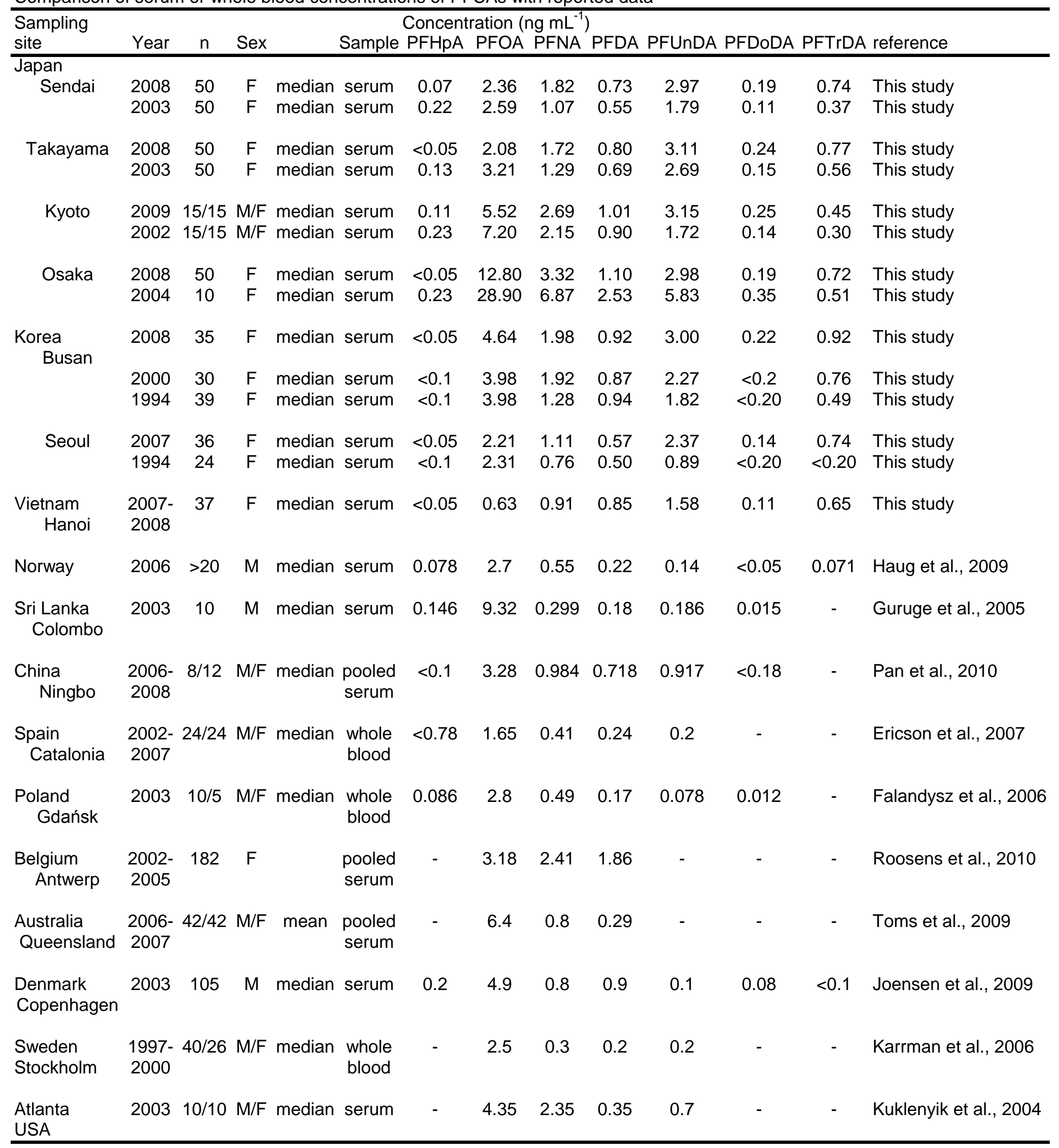


supplemental Figure 1

A

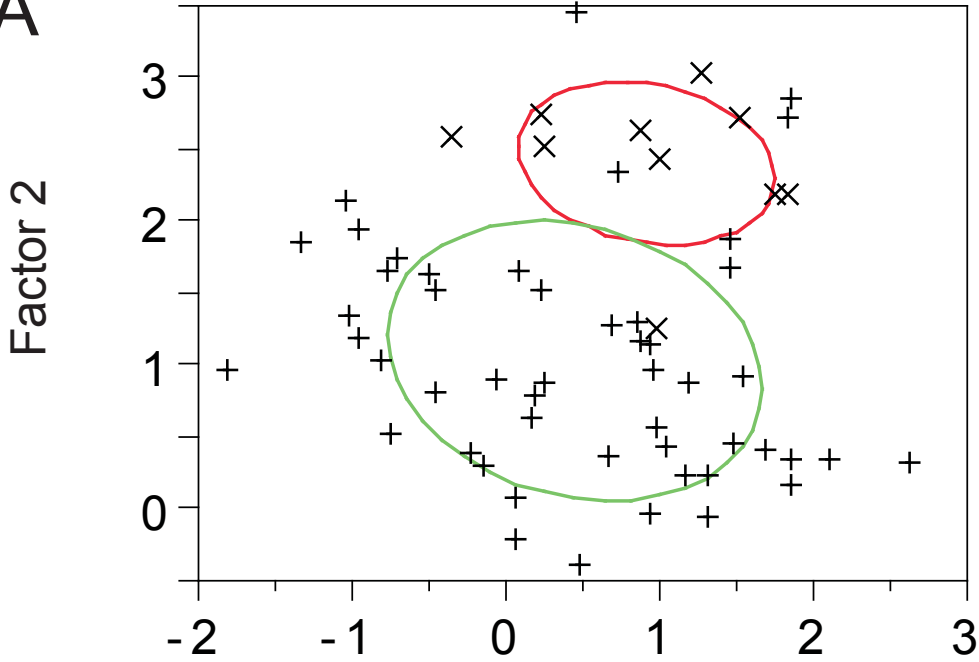

Factor 1

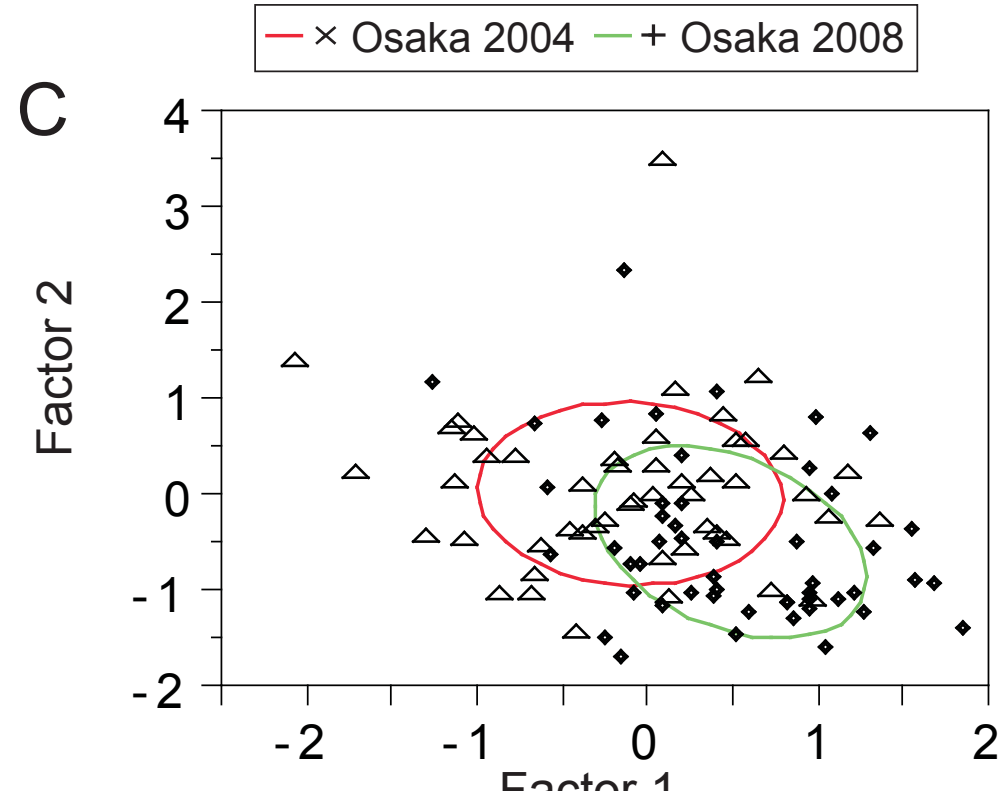

Factor 1

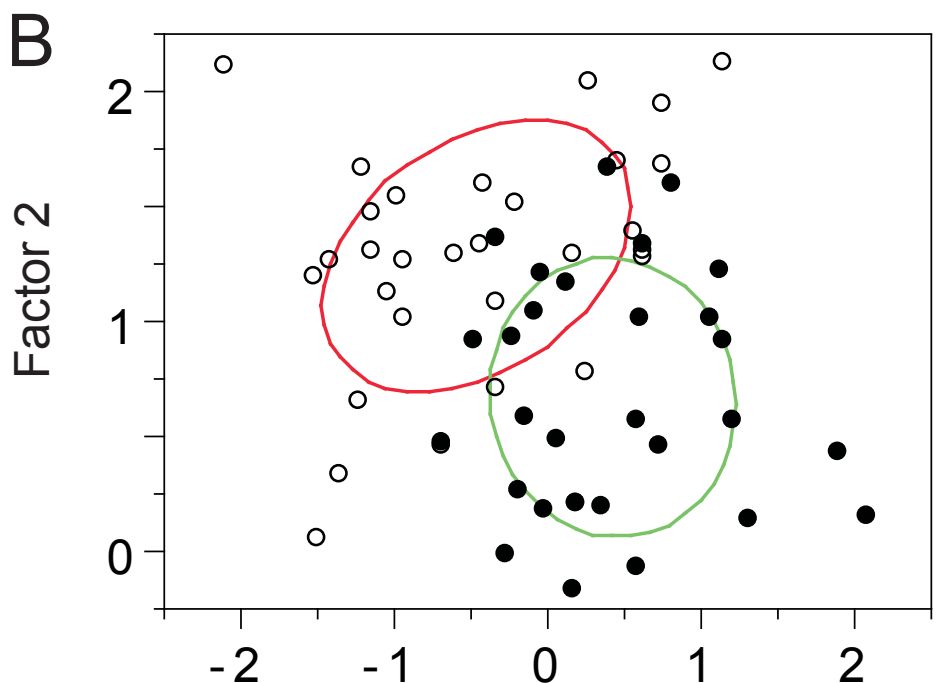

Factor 1

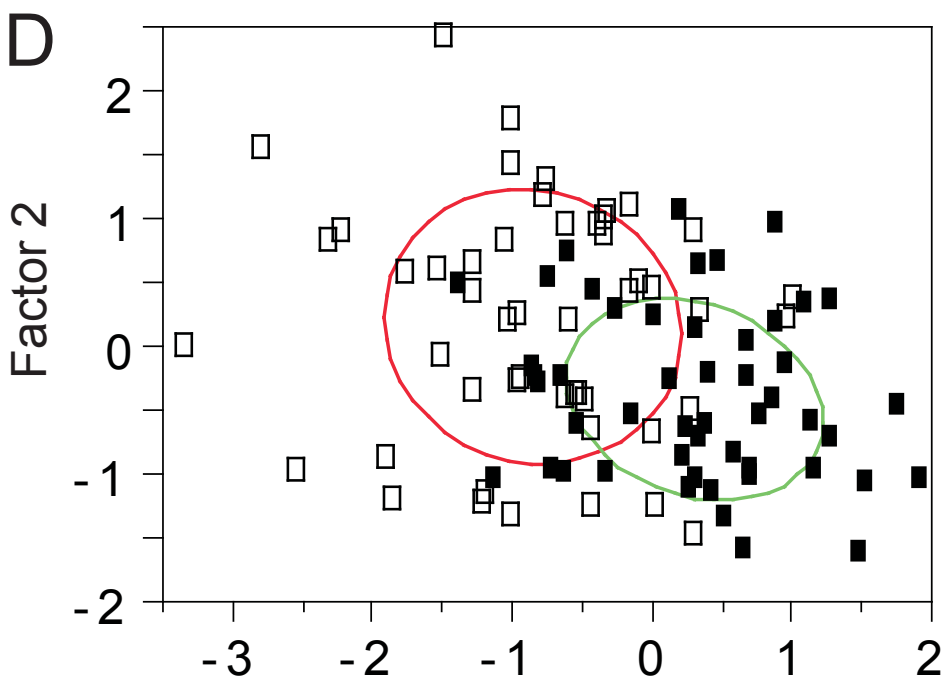

Factor 1

\section{— uSendai 2003 - - Sendai 2008}

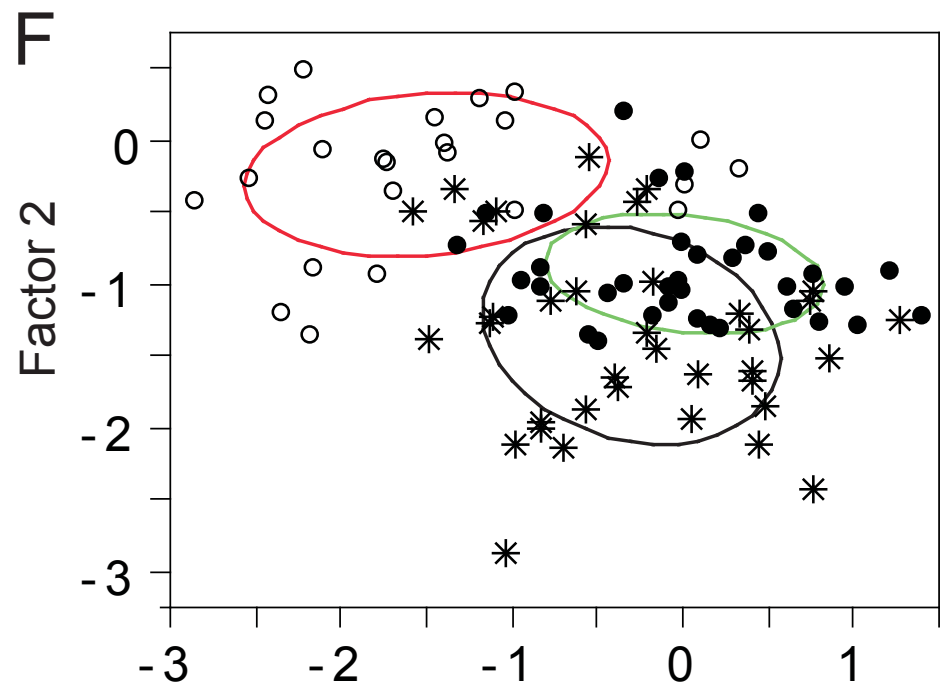

Factor 1

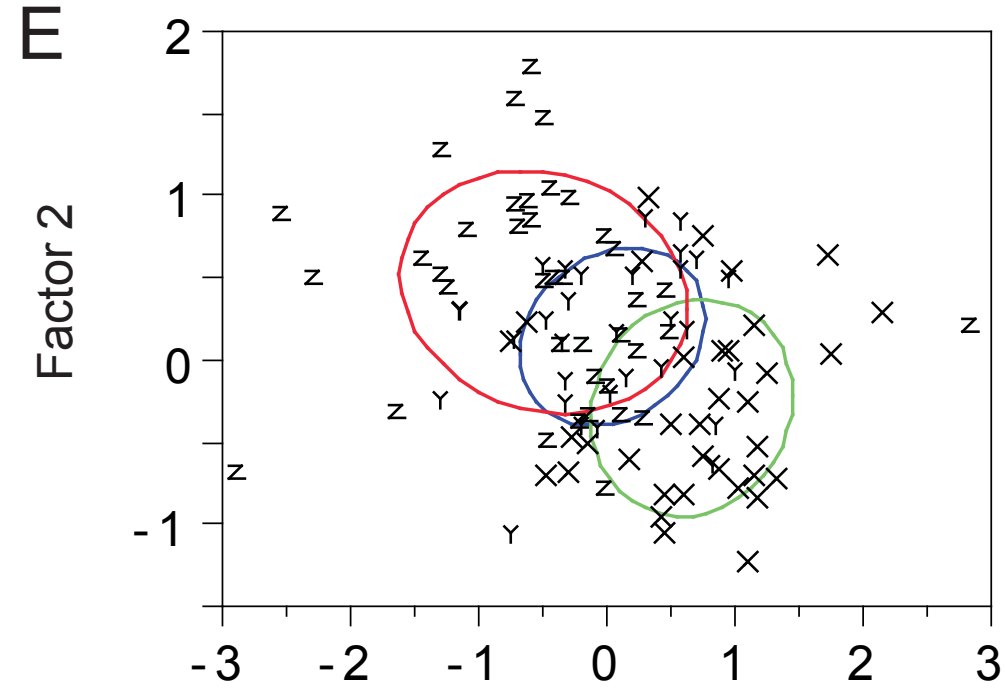

Factor 1 